\title{
Spatial evolution path of Gulangyu Island historical international community: from the perspective of actor-network theory
}

\author{
Yuan Li', Jing Guo ${ }^{2}$, Long Zhao ${ }^{3}$, Yiping Chen ${ }^{4 *}$, Cheng Wang ${ }^{4}$, Cheng Wang ${ }^{5,6}$ and Jonathan $\mathrm{Li}^{7^{*}}$
}

\begin{abstract}
Gulangyu Island is a special case of social development and changes since modern China. In the past, Chinese and foreign people lived together and Chinese and Western cultures coexisted, resulting in an international community with outstanding cultural diversity and modern quality of life. As a functional carrier, space is of great reference significance to the research on the spatial evolution path of the Gulangyu international community with the accelerating globalization and rapid expansion of urbanization. Based on the interpretation of historical maps and the integration of historical geographic information, this paper explores the evolution path of Gulangyu community space in modern times from the perspective of actor-network theory. It is found that: (1) The change of key actors promotes the spatial evolution of the Gulangyu international community. (2) In the stage of foreign culture dissemination (1840-1902), foreign nationals, as key actors, promoted the formation and development of actor-networks through administrative recruitment and other means, and promoted Gulangyu Island to change from a traditional Minnan community to a modern community form, with the embryonic form of an international community beginning to emerge. (3) In the stage of multicultural integration (1903-1940), overseas Chinese returning home became key actors. The concept of a combination of Western cultures was not only embodied in community management but also acted on space practice to promote the multicultural integration of the Gulangyu international community. This paper summarizes the effects of various factors on the evolution of community space, to provide a reference for other coastal cities to rationally develop islands and promote the multicultural integration of local communities.
\end{abstract}

Keywords: Actor-network theory, Historical international community, Spatial evolution, Historical geography, Gulangyu Island

\section{Introduction}

World cultural heritage is an international convention system for the purpose of preserving cultural places with universal value for human beings all over the world, and it is the highest level of cultural protection and inheritance [1]. Human civilization has formed a large number of precious cultural heritages. However, large number of

\footnotetext{
*Correspondence: chenyiping@xmu.edu.cn; junli@uwaterloo.ca

${ }^{4}$ Fujian Key Lab of Sensing and Computing for Smart Cities, School

of Informatics, Xiamen University, Xiamen 361005, Fujian, China

${ }^{7}$ Department of Geography and Environmental Management, University

of Waterloo, Waterloo, ON N2L 3G1, Canada

Full list of author information is available at the end of the article
}

precious cultural heritages. However, due to the influence of natural changes and human activities, cultural heritages are inevitably eroded and destroyed. How to preserve, inherit and spread the precious cultural heritage of mankind through modern scientific and technological means is an important historical mission of contemporary people, and it has also become a major issue facing the whole world [2]. On July 8, 2017, Gulangyu Island in Xiamen was listed on the World Cultural Heritage List by UNESCO at the 41st World Heritage Conference held in Clough, Poland, and officially became the 52nd World Heritage Site in China. Gulangyu Island is famous for its reputation as a historical international community, as

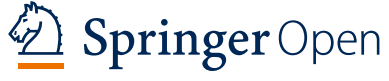

(c) The Author(s) 2021. Open Access This article is licensed under a Creative Commons Attribution 4.0 International License, which permits use, sharing, adaptation, distribution and reproduction in any medium or format, as long as you give appropriate credit to the original author(s) and the source, provide a link to the Creative Commons licence, and indicate if changes were made. The images or other third party material in this article are included in the article's Creative Commons licence, unless indicated otherwise in a credit line to the material. If material is not included in the article's Creative Commons licence and your intended use is not permitted by statutory regulation or exceeds the permitted use, you will need to obtain permission directly from the copyright holder. To view a copy of this licence, visit http://creativecommons.org/licenses/by/4.0/. The Creative Commons Public Domain Dedication waiver (http://creativeco mmons.org/publicdomain/zero/1.0/) applies to the data made available in this article, unless otherwise stated in a credit line to the data. 
the epitome of the cultural history of the coexistence and integration of multiculturalism, Ms. Irina Bokova, Director-General of UNESCO, once commented: "Although Gulangyu Island is small in area, it is of great value and profound cultural heritage, which reflects the dialogue between different cultures and faiths. This dialogue can help people all over the world understand and practice the value of respect and tolerance and appreciate diversity. This is an important classroom for global citizenship." [3]

However, it is a difficult task to explore the spatial evolution of cultural heritage. The existing historical map data are scattered, and a large amount of valuable information is submerged in classical literature. This irregular information undoubtedly brings a certain influence to the study of historical evolution. From the historical data, we can roughly describe the changes of the city's form. Scholars have done a lot of research in this area, such as analyzing the urban area and urban system pattern under typical historical sections through historical documents and historical maps [4], or analyzing the change process of a single city in the past century in combination with historical data [5]. However, this kind of research results are mostly presented in the form of words, so it is difficult to unify the spatial historical evolution into an integrated digital Geographic Information System (GIS) database for superposition analysis of spatial evolution. With the development of GIS technology, the interpretation of spatial evolution information from historical maps has made great progress. It can not only reproduce historical maps but also integrate multiple historical data into the same geographic information database, which is convenient for vertical comparison between different years.

Many scholars try to quantify the spatial law of historical evolution by digitizing traditional paper historical maps and then using GIS. Gregory uses the Historical GIS to make statistics on the human geographic information of Britain in the past two centuries [6]; Schuppert reconstructs the cultural landscape near the early Celtic throne in southern Germany based on GIS, and explores the ecological and economic factors that contributed to its origin and development [7]; Kim used Web GIS to analyze the landscape change of Singapore historical map (1828-2015), and found the survival and disappearance of local identity [8]; Zohar used a historical geographic information system to investigate the development of routes in the Negev region from the beginning of the twentieth century to the end of the twentieth century [9]. Although more and more scholars begin to try to use GIS for historical research, the results often only stay in data compilation or descriptive analysis of landscape changes. At the same time, traditional research lacks a systematic theoretical system and is difficult to reveal the mechanism of spatial form evolution in depth.

City is the symbol of human civilization and the product of social development to a certain stage. Only by combining the operation track of capital and power under a specific social form and the behavior motivation of various interest groups in the social process can we fully explain the mechanism of spatial form change [10]. It is of great reference significance and data value to analyze the development of Gulangyu historical international community through GIS digital technology. At the same time, actor-network theory, as a frontier theory to explore the dynamic relationship of spatial evolution, can explain the process and influencing factors of spatial evolution completely and is an important supplement to study the spatial evolution of historical international communities.

To sum up, the two main problems solved in this paper are: (1) Taking Gulangyu Island as an example, the interpretation of historical maps and the integration of geographic information; (2) Exploring the evolution path of the spatial form of international historical communities from the perspective of actor-network.

Our main contribution is twofold:

From the application point of view, this paper proposes a heritage research method for historical map recognition, which uses GIS to visualize the traditional spatial evolution research.

From the perspective of methodology, this paper proposes to apply the actor-network theory to heritage science, and qualitative research is helpful to understand the mechanism behind the disappearing historical space.

At the same time, this study also helps to deepen the understanding of the evolution and reconstruction of historical communities, and provides a reference for the integration of diverse communities and the protection of heritage communities under the background of contemporary globalization.

The structure of the article is as follows, section "Literature review" introduces the research work related to this paper, section "Study area and research method" introduces the research area and research methods, section "Community space evolution in the stage of foreign culture dissemination (1840-1902)" and section "Community space evolution in the stage of multicultural integration (1903-1940)" introduces our research results, including historical map recognition results and the use of actor-network theory to explain its spatial evolution path, section "Discussion and conclusion" launches discussion and conclusion, introduces the internal mechanism of heritage spatial evolution, and summarizes the full text. 


\section{Literature review}

This section aims to develop the theoretical framework of this research, which involves two main research directions: spatial form evolution and actor-network theory. It provides ideas and methods for this research by summarizing the past research.

\section{Evolution of spatial form}

"Space" has always been the core topic of geography and urban and rural planning, and has become increasingly complicated under the background of globalization. Space is no longer an instrumental container but is regarded as a place for the reproduction of local social relations [11]. The connotation of space has evolved with the three changes of human geography, namely, "regional difference-spatial analysis-social theory" [12], which makes people have different understandings when explaining the concept of "space". Many scholars have explored the evolution of urban space from the perspective of material form; Wang copied the spatial evolution of the city through participatory historical map translation (PHMT), identified the urban heritage with the key elements of landscape structure, and visualized its heritage value with GIS [13]; Jiang used historical documents, ancient maps, mapping maps of the Republic of China and remote sensing images to restore the expansion process of urban spatial form in 56 cities in Jiangsu and Shanghai since the Ming Dynasty [14]; Through the combination of picture trimming and remote sensing geographical analysis, Lin reviewed the urban development of Xiamen Island in the past 100 years, and discussed the potential factors of island urban expansion from the aspects of planning, industry, topography and population [15].

On the other hand, some scholars pay attention to the local social culture of urban space and interpret the community cultural space of Gulangyu Island. Based on archival data and on-site investigation, Chen described the conflicts, negotiations and compromises of different groups during the development of Gulangyu Island in the semi-colonial era (1903-1937), and pointed out that it cultivated a new model with Xiamen characteristics in terms of urban construction, governance and living environment [16]; Based on the analysis of historical documents, Lv explained the heritage elements, urban spatial mechanism, architecture and landscape of Gulangyu International Historical Community, and analyzed its cultural connotation value [17]; Qiu based on the perspective of narratology, introduced the quantitative method of spatial syntax to quantitatively explain the spatial rights representation, functional representation and characteristic representation of historical urban areas in cultural space [18]; In addition to the spatial understanding of material and society, with the development of information and communication computing, more scholars have abstracted space and interpreted space from the perspective of mobility and network. Li used the combination of GIS and GPS to explore the network characteristics of tourism flow on Gulangyu Island [19].

The existing research provides an important reference for understanding the spatial evolution of international historical communities, but the excavation of social relations and action paths behind the spatial evolution of communities is insufficient. Few studies combine material space with social space to fully explain the spatial evolution of Gulangyu historical communities and its influencing factors. In order to eliminate the binary opposition between material space and social space, local space and mobile space, and to understand the mechanism of spatial evolution more comprehensively and profoundly, it is necessary to introduce a new perspective to explore the social relations behind material space and its action path.

\section{Research on actor-networks theory}

Actor-Network Theory (ANT) is a social science research method that relies on the network system model to present the dynamic relationship between actors [20]. The theory originated in France in 1980s, and its main representatives are Michel Cuarón [20], Bruno Latour [21], and John Law [22]. ANT claims that actors are heterogeneous, including not only human beings, but also inanimate non-human actors, such as nature, artifacts, ideas and concepts. Human and non-human actors are intertwined in practice, resulting in a dynamic, inseparable and evolving hybrid network [23].

Many scholars use actor-network theory to carry out research in different dimensions; For example, Murdoch pointed out that in the new era of social transformation and economic transformation, the new order must be explained by the description of actor-network construction [24]; Koo took South Korea's elderly industry as an example to study the relationship between geography and network dynamics in the evolution of emerging industries [25]; Becerril used the actor- network theory (ANT) and the public policy tool political sociology theory (PPI) to deeply discuss the development process of slum upgrading in Rio from 1993 to 2012 [26]; Figueiro used the actor-network theory to explore the effectiveness of health interventions in northeastern Brazil and analyze and describe the complex dynamic evolution of crosssectoral international relations [27]; Yan introduced the perspective of actor-network to investigate the co-evolution and internal motivation of therapeutic landscape and health tourism [28]; Taking Zhouzhuang Town as an 
example, Wang explained the action path of actors in the spatial evolution of ancient towns in different stages of tourism development by using actor-network theory [29].

Generally speaking, ANT is widely used in geography, economy, politics, medical treatment, environment, tourism and other research fields. The spatial view of actor-network can be summarized as heterogeneous and translated topological space. First, the topological space of actor-network is obviously different from Euclidean three-dimensional space. In topological structure, distance and scale are the effects of relationship, that is, the construction of relationship forms space. Second, the cyberspace of actors is heterogeneous. Non-human actors are no longer just material resources or constraints but actively intervene in actions. They "juggle" among human actors, "transform, translate, distort and modify the elements or meanings they carry", which makes the linear chain dominated by human actors "refract", thus guiding actions in unexpected directions, and then shaping the network-like spatial form; Third, the actornetwork is connected by "translation". The translation is generally divided into four stages: Problematization, Interestement, Enrolment and Mobilisation [20-22]. From a qualitative point of view, the actor-network theory has shaped a relational topological structure space, which is helpful to dispel the binary opposition between place and globalization. Its core idea provides a conceptual framework for analyzing the increasingly complex social space hybridization [30].

This paper chooses this analytical tool as a theoretical framework to explore the spatial evolution of Gulangyu historical international community, the reasons are as follows: First of all, Latour's empirical research method is suitable for this research. ANT is good at analyzing the relationship between the materiality and sociality of space, and unifies the traditional "Space of place" and the "Space of flows" promoted by globalization into "Space of actor-networks" made by practice [31]. Secondly, the actor-network theory represents a frontier field, which is also suitable for the object of this paper. Thirdly, based on the consideration of better interpretation research, previous studies focused on the interpretation of space construction from the perspective of human actors, while ignoring the interpretation of non-human actors, unable to show how various actors are interconnected to promote the construction of space. The historical international community is the result of the role of multiple actors in different stages. Therefore, the actor-network theory can provide a powerful framework for the spatial evolution of the historical international community. The introduction of this perspective is conducive to the analysis of the interactive logic between different actors and between actors and spaces, and has guiding significance for the understanding of the evolution path of international historical communities and the subsequent heritage protection.

To sum up, as a qualitative study, taking Gulangyu Island as a typical case, based on the digitization of historical maps in GIS and the theory of actor-network, this paper analyzes the actor-network in different development stages of Gulangyu Island, discusses how it leads to the change of space users and functions, and then promotes the change of community material space form, and provides a new explanation path for the spatial evolution of the international historical community.

\section{Study area and research method \\ Study areas}

Gulangyu Island belongs to Xiamen City, Fujian Province. It is located at the mouth of Jiulong River in the south of Fujian Province (hereinafter referred to as "Minnan") on the southeast coast of China. It is an island in Xiamen Bay and faces Xiamen Island across the 600-m-wide Lujiang Strait (Fig. 1).

Gulangyu Island was uninhabited for a long period of time in history. The great geographical discovery in the fifteenth century involved Minnan in the first wave of globalization. Maritime trade and maritime economic activities brought Minnan immigrants into Gulangyu Island and became traditional local settlements [32]. In 1843, Xiamen opened its trading port. In 1903, Gulangyu Island established an international community. This island, located in the southern coastal area of the Chinese Empire, became an important window for exchanges between China and foreign countries at that time. The heritage embodies the comprehensive characteristics of modern residence, and its remains include 931 historical buildings, natural landscapes, historical road networks and gardens showing different local and international styles. Because of the joint efforts of local Chinese, returned overseas Chinese and many foreign residents, Gulangyu Island has developed into an international community with outstanding cultural diversity and modern quality of life. At the same time, Gulangyu Island has also became an ideal living place for overseas Chinese and elite active in East and Southeast Asia. In addition,

Gulangyu Island also concentrated on the modern human settlement concept from the mid-nineteenth century to the mid-twentieth century. Gulangyu Island is a unique example of cultural integration, which comes from cultural exchange, and this cultural exchange is still clearly visible through the organic urban texture preserved to this day. Gulangyu Island was listed as a world cultural heritage in 2017, and the evolution of its community spatial form is of typical significance, which is worth reviewing and exploring. 


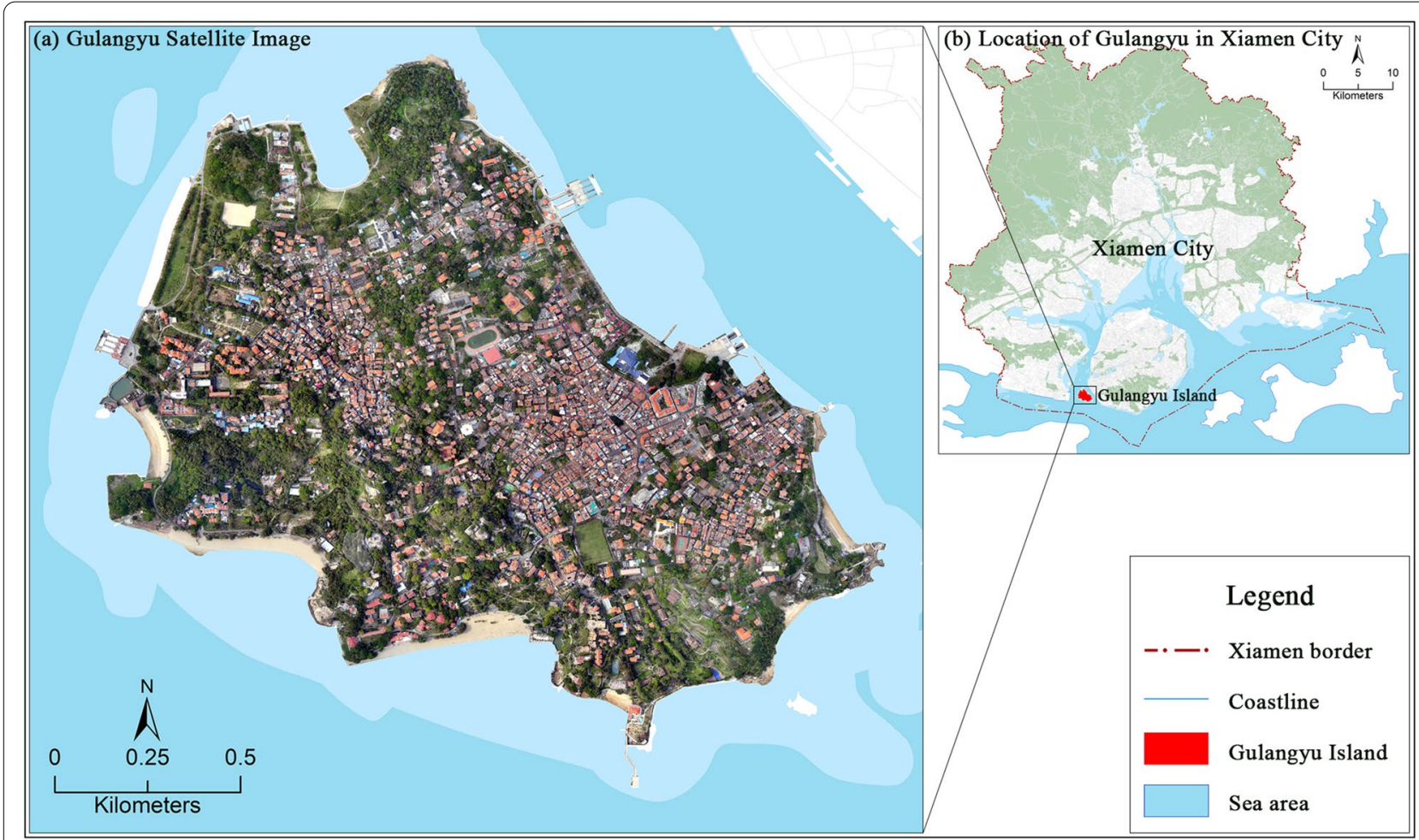

Fig. 1 Map of the study area

The spatial evolution of the Gulangyu International Historical Community has obvious stage characteristics. It has successively experienced the period of local cultural accumulation (before the Opium War), the period of foreign cultural dissemination (from the Opium War to the signing of the Public Land Boundary Charter in 1902), the period of multicultural integration (from 1903 to the outbreak of the Pacific War) and the spatial transformation of the post-international community (from 1941 to the present) [33]. According to the change of participants, this paper focuses on explaining the characteristics of the community spatial evolution path in Gulangyu Island during the period of foreign culture dissemination and the period of multicultural integration.

\section{GIS interpretation of historical map}

Under the background of "digital humanities" and the concept of big data, the informatization of historical geography can reproduce the scene at that time. At present, the research on historical geography is still not detailed enough, and many historical environment elements and information on the map have not been discovered and applied. This study draws lessons from the concept of "cultural layer" in archaeology, discriminates the disappeared historical sites based on hierarchical thinking [34], and uses culture as a clue, time as a sequence, and space as a carrier to carry out geographical registration and digital translation of historical maps. Data processing includes three steps:

First, the collection of historical maps and documents. The historical map materials applied come from Xiamen Library and British Library (Fig. 2). These materials are the basic materials to explore the scale, form and changes of Gulangyu Island.

Second, the extraction of historical elements of Gulangyu Island. This paper mainly extracts the island scale, architecture, road network and other elements of Gulangyu Island by GIS vectorization. Identify the spatial function of this element in history through the annotation on the map corresponding to the cultural and historical data of Gulangyu Island [35].

Third, the establishment of GIS database. Since most of the historical buildings on Gulangyu have been completely preserved, architects, urban planners and other personnel have also established archives on the buildings on Gulangyu Island. Therefore, the historical map information is interpreted hierarchically by referring to the protection planning of historical buildings on Gulangyu Island [36], combined with contemporary measured building statistics, high-definition remote sensing images, digital elevation models and historical documents. Identify the disappeared international historical 

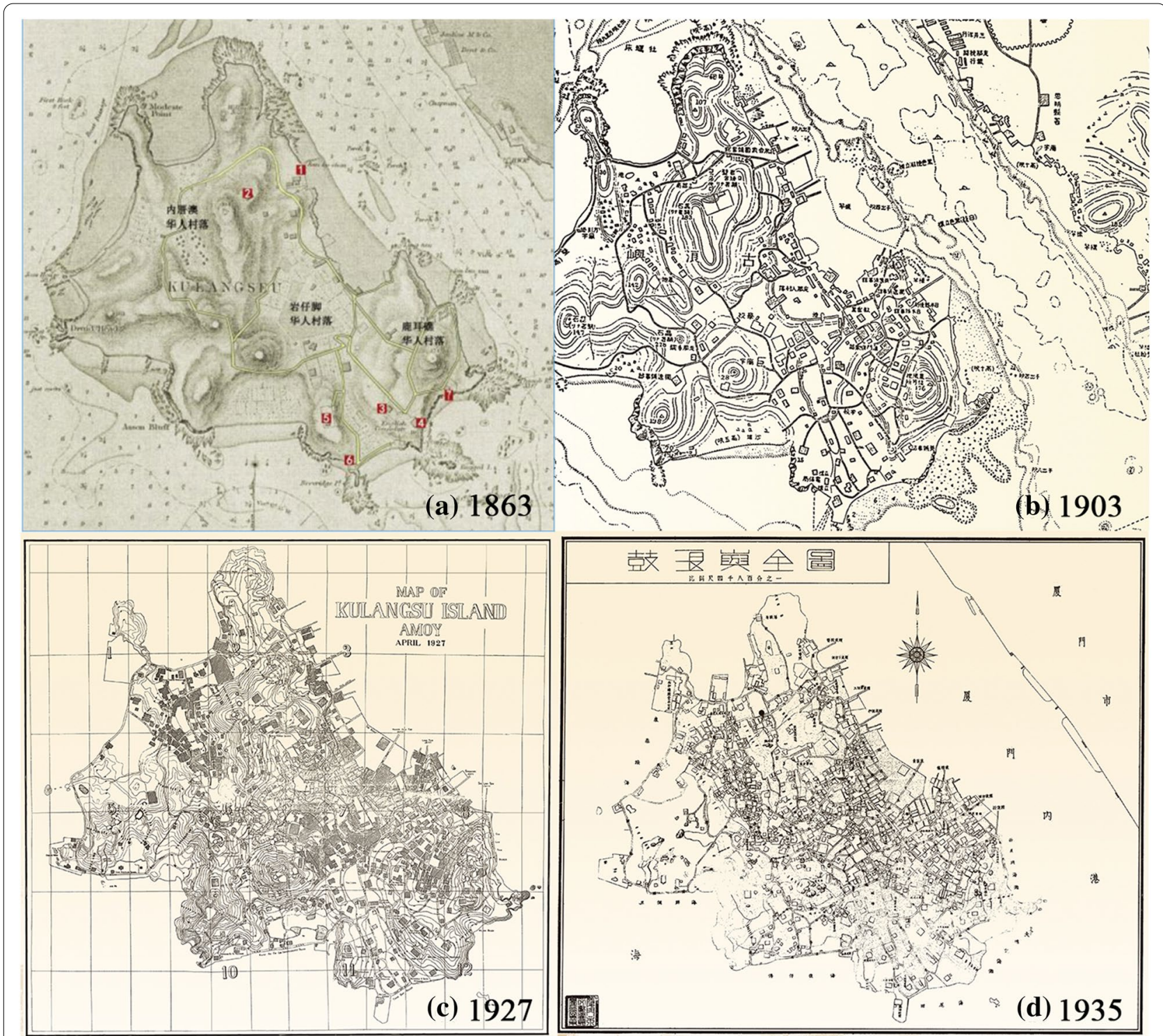

Fig. 2 Historical map of Gulangyu in four periods

community relics from the three levels of point, line and surface, establish the attribute table of historical coastline, buildings and roads, and integrate them into the GIS database for overlay evolution analysis.

\section{Actor-network theory}

Actor-network theory (ANT) includes three core concepts: actor, translation and heterogeneous network [20]. Actors refer to all factors in the process of scientific practice, it includes both human actors and non-human materials and ideas. Different actors are heterogeneous in terms of interest orientation and behavior. The stability of the network depends on the continuous translation of the interests of various actors. The power to deviate from the network may occur within the network due to objections. The key link of actor-network research is translation, that is, four basic links: Problematization, Interestement, Enrollment and Mobilization (Fig. 3).

"Problematization" makes the objects concerned by different actors problematic, thus forming a network alliance, and at the same time makes the problems of core actors become "Obligatory Points of Passage" (OPP) to achieve the goals of other actors; "Interestement" strengthens the definition of actors' roles in the problem presentation process through various devices and strategies; As a result, actors are "Enrollment" to become 


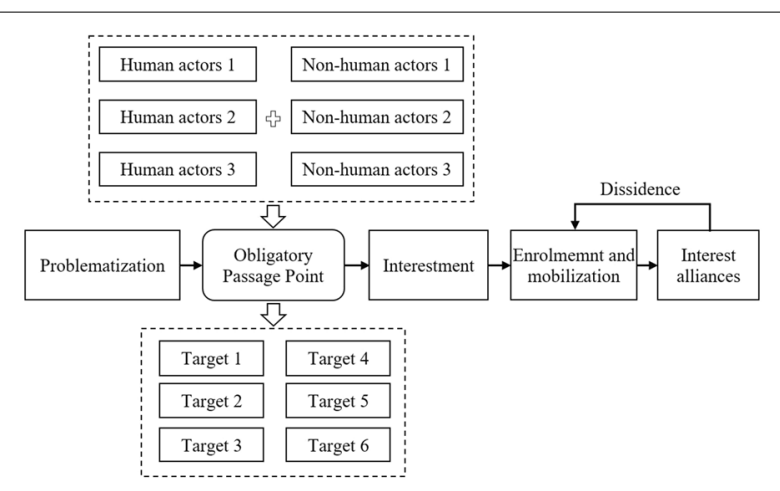

Fig. 3 Schematic diagram of actor-network translation process

members of the alliance; "Mobilization" means that the proponent rises to the Spokemen of the entire network alliance and exercises power over other alliance members to maintain the stable operation of the network. In the process, objections may need to be overcome. Translation by actors may lead to changes in meaning, relationship, and rights, so it is a "dynamic network". Actor-Network Theory brings all factors from society and nature into a unified interpretation framework, which is suitable for explaining the functional process of spatial evolution of community form in different stages.

\section{Community space evolution in the stage of foreign culture dissemination (1840-1902) \\ Composition of the network of actors}

Before the Opium War, Gulangyu Island followed the traditional economic model of farming and fishing. There were about 100 families and more than 1000 people on the island. Neicuo'ao, Luer Reef, and Yanzijiao are dominated by the Huang's clan, while the Tianwei area is dominated by Hong's clan. The residents of the island follow the belief and customs of the Minnan people who believe in gods and worship many gods. There are Sunlight Rock Temple of Buddhism, Zhongde Palace, and Xingxian Palace dedicated to the Baosheng Emperor on the island. After the Opium War, different actors jointly promoted the construction of actor alliance based on their own goals, to encourage foreigners to assume key actors. Actors include administrative units: Qing government and consulates of various countries; Community groups: Aborigines, consular officials and their families, Western businessmen, missionaries, and other foreign nationals. Non-human actors mainly include material elements: landscape resources, traditional dwellings, and public space; Conceptual elements: local conditions and customs, traditional religions (Table 1). The ompulsory passage point (OPP) shared by the above actors is "the embryonic form of the international community". As shown in Fig. 4, it shows the problems that different actors expect to solve and the goals to be achieved.

\section{Actor translation process}

Translate the goals of multiple actors, give benefits to all actors, and remove obstacles to action. At this time, the foreign nationals on Gulangyu Island acted as the helm, leading a few leading actors to make more actors join the network alliance by recruiting and being recruited, to maximize the benefits. The translation process in actornetwork creation as shown in Fig. 5 is formed.

First, administrative recruitment. Western countries signed the Treaty of Nanking with the Qing government, Forcing Xiamen to open its trading port, The British troops were stationed in Gulangyu Island. The signing of a series of treaties and subsequent clauses allowed the British to lease land and houses at trading ports. The subsequent signing of the Sino-US Wangxia Treaty and the Sino-French Huangpu Treaty enabled foreigners to obtain consular negotiations, missionary work, and the right to set up hospitals. More and more countries have consular offices located in Gulangyu Island.

Second, the fund Committee call up. By the 1870s, there were nearly 200 foreign nationals in Gulangyu Island. At that time, there was little to say about the island. There were no recreational facilities and commercial facilities. There was not even a road in the modern sense. The sanitary conditions were extremely poor. To improve the quality of social life, western countries set up the Gulangyu Road Cemetery Fund Committee in 1880 to invest in urban construction through tax payment,

Table 1 Composition of actors in the stage of foreign culture communication

\begin{tabular}{lll}
\hline Related composition & Category & Content \\
\hline Human actor & Administrative unit & The Qing government, Consulates \\
& Community group & Aborigines, Consular officials and their families, Foreign \\
non-human actor & Material element & Landscape resources, Traditional dwellings, Public spaces \\
& Conceptual elements & Local customs and practices, Traditional religions \\
\hline
\end{tabular}


bringing the culture of social public space governance into Gulangyu.

Third, housing and landscape recruitment. In 1853, Forced by the attack of the Knife Rebels, Foreigners in Xiamen poured into Gulangyu Island to "take refuge". Soon they found that Gulangyu Island, which is located in a corner, seems safer and more comfortable. Gulangyu Island has gradually become the main residence for foreigners in southern Fujian. At first, it rented local houses for accommodation and work, and the high rent made the aborigines willing to trade with it. For example, the existing ancestral hall (Huang shi xiao zong, 黄氏小宗) was the foothold of missionary Abeel and doctor Gan Ming who first came to Xiamen to preach, and then gradually began to buy land to build their own houses.

Fourth, cultural recruitment. Western missionaries were not recognized at first and even expelled from villages where ethnic groups lived. Then schools and hospitals were set up to train Chinese priests and spread Christianity in southern Fujian by waiving tuition fees, providing accommodation, accommodating many poor children and abandoned babies.
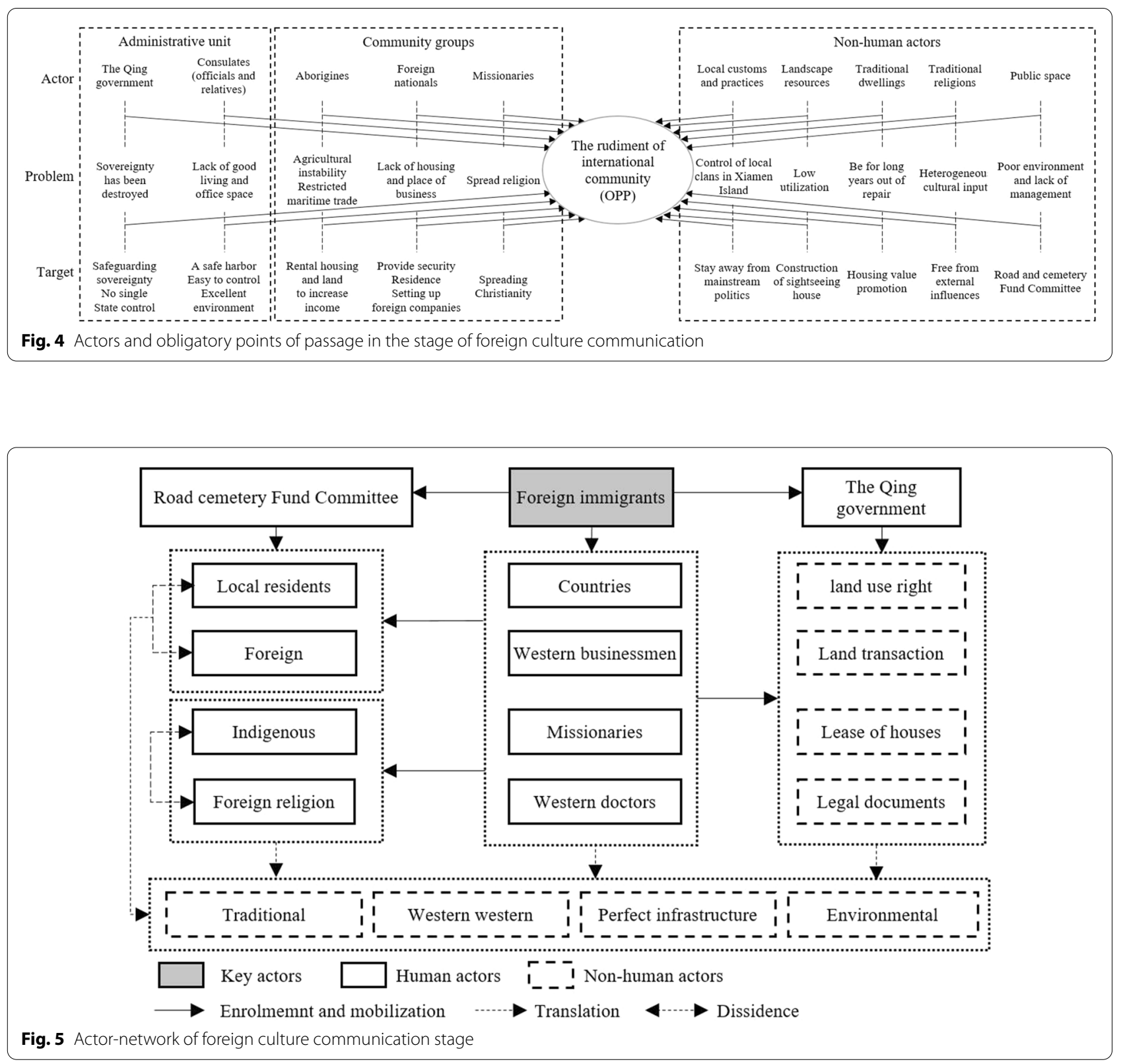


\section{Community spatial evolution with the intervention of heterogeneous actors}

Different aims and behaviors of heterogeneous actors not only shape social networks but also reproduce and construct the spatial characteristics of Gulangyu Island. The island space has changed from a space for local people to live and fish and cultivate to a multi-functional composite space shared by local people, foreign nationals, and consulates of various countries. The function and form of the space have changed (Fig. 6).

In the stage of local cultural accumulation, the local settlement is roughly divided into three areas: Neicuo'ao, Yanzijiao, and Luer Reef, which are scattered in the flat land facing the sea. A large amount of land serves and fishes the farming economy. Traditional religions such as Sunlight Rock, Zhongde Palace, and Xingxian Palace are dotted sporadically, which is the public cultural activity space of the aborigines. The original road is rugged and complex. Guided by buildings and natural conditions, it basically follows the distribution of mountain-shaped terrain or buildings. The angle changes a lot, is irregular, and often deviates.

In the stage of foreign culture dissemination, consulates of various countries have chosen this site one after another. Western-style buildings with veranda architectural style are mostly chosen on the mountains and by the sea, making full use of the island landscape resources and having a certain space distance from the aborigines. Foreigner firms rely on the wharf on the east side of Gulangyu Island to form commercial storage facilities on the east side of the island.

At the same time, the number of roads on the island has increased, mainly connecting the residences of foreign nationals and the traffic between the residences and docks, basically forming a three-circle road system. One circle is the northern ring road around Bijia Mountain, connecting the residential area of Neicuo'ao in the western part of the island with the eastern part of the island; One circle is the Sunlight Rock Ring Road to the south and the Yanzijiao Ring Road to the east, connecting the traditional settlement of Yanzijiao; One circle is the Luer Reef Ring Road in the southeast, which surrounds the Luer Reef residential area; Many radial roads leading to docks and beaches on the seashore have been built from the three-circle ring road, forming the basic framework of Gulangyu traffic.

In addition, churches, schools, and hospitals serving the spread of Western religions have emerged, municipal infrastructure such as cemeteries, and recreational facilities such as clubs and stadiums have emerged. Generally speaking, foreign nationals played a direct role in the spatial evolution of Gulangyu Island during this period. By the end of the nineteenth century, Gulangyu Island had more than 10 consulates, 6 church schools, 5 churches, 2 foreign-run hospitals, telegraph offices, and several foreign firms, as well as many private houses all over the island. The formation of a situation in which local ethnic groups and foreign foreigners live separately and coexist peacefully has begun to take shape in the embryonic form of an international community.

\section{Community space evolution in the stage of multicultural integration (1903-1940)}

In 1902, western countries and Japan competed for power in Gulangyu Island, forcing the Qing government to sign the "Xiamen Gulangyu Public Land Boundary Regulations" with western countries, set up the Ministry of Industry as the management organization, and issued the "Gulangyu Ministry of Industry Regulations" as the specific rules for municipal administration. Gulangyu Island realized multi-country co-management and integrated guardianship. The goal intention of the actor-network is usually the same as that of the key actors. With the First World War and the change of the world pattern, a large number of overseas Chinese from southern Fujian who returned home became the emerging social group that dominated the settlement pattern and spatial evolution pattern of Gulangyu Island, gradually replacing foreign nationals and becoming key actors. The reconstruction and re-deduction of the actor-network promoted the further evolution of Gulangyu community space.

\section{Changes in the composition of the network of actors}

With the improvement of Gulangyu's infrastructure and the emergence of modern communities, the mandatory point of the passage (OPP) of the actor-network in the stage of multicultural integration has also changed to "multicultural integration of international communities", and several new heterogeneous actors have joined the network alliance. The newly added actors mainly include human actors such as the Ministry of Industry, the Japanese government, overseas Chinese, and non-human actors such as capital, land resources, residential features, industrial structure, political environment, laws, and regulations (Table 2 and Fig. 7).

\section{Re-interpretation of the actor's translation process}

With the change of key actors, new heterogeneous actors are re-recruited and recruited.

First, administrative Recruitment: During the period of the public concession, the administrative organization has always been the Ministry of Industry under the leadership of the board of directors. Its function is to "take charge of matters that should be handled within the community", including public security, taxation, patrol, health facilities, public facilities, and markets. Gulangyu 


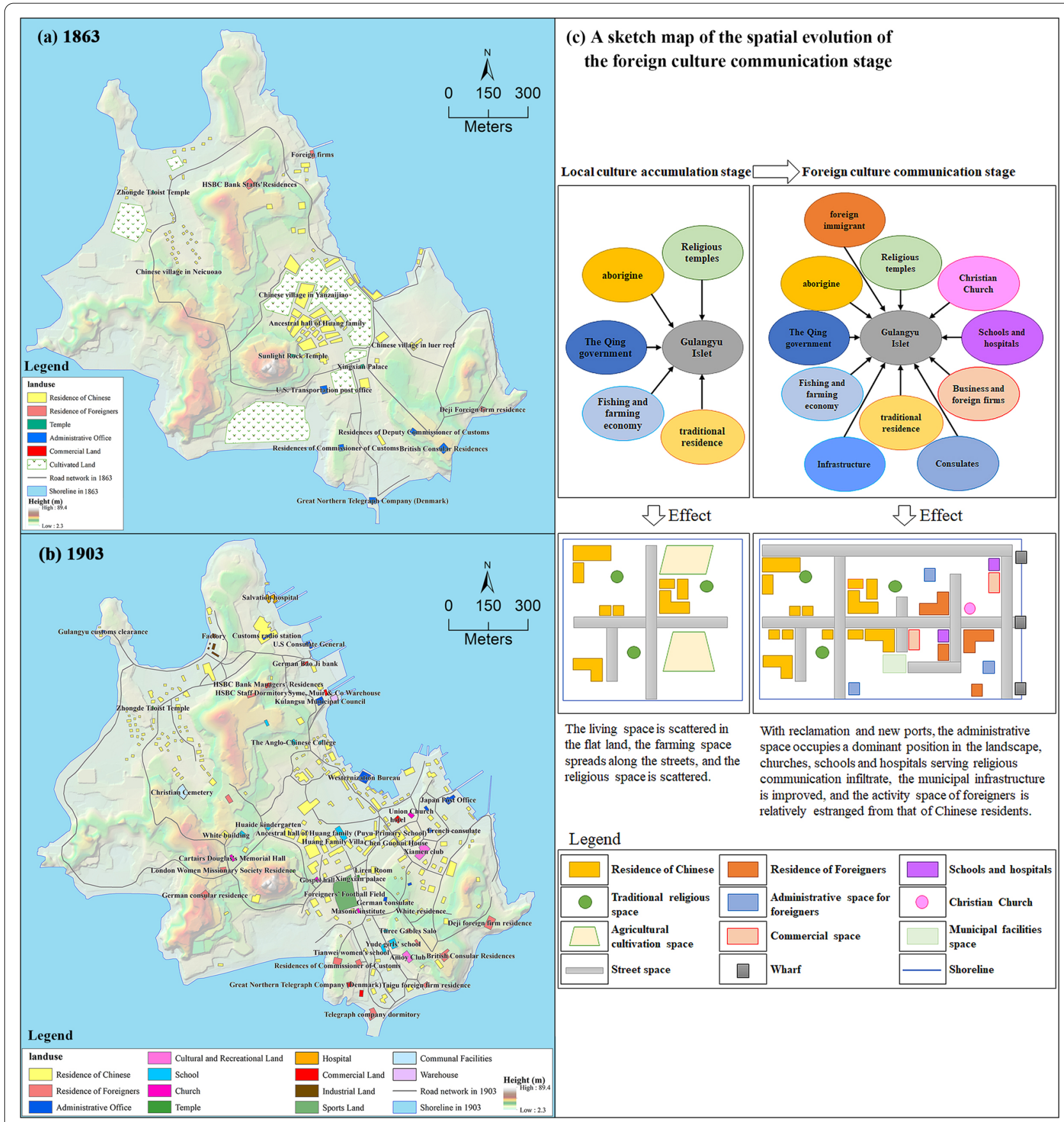

Fig. 6 Spatial evolution of Gulangyu under the intervention of heterogeneous actors

Island is inhabited not only by foreign nationals but also by legal disputes between Chinese and foreign countries and between Chinese in the community. In the community, there is a Chinese judicial institution-joint hearing court, which is one of the few Chinese institutions that can play a practical role in Gulangyu Island. The Ministry of Industry's promotion of Gulangyu community municipal construction has caused great shock in the Chinese community. Overseas Chinese groups have strengthened their awareness of participating in community construction and have the desire to transform the city's appearance. Overseas Chinese groups not only joined the board 
of directors of the Ministry of Industry but also played an obvious role in recruiting other actors. They actively formed social organizations and successively established the Chinese Taxpayers Association, the Chinese People's Association, and the Chinese Council to safeguard their rights and interests and promote social reform.

Second, fund recruitment. Overseas immigrants from southern Fujian who returned home with abundant capital set up industries, built houses and infrastructure in Gulangyu Island. The community's water supply, power supply, road traffic, communication, the ship crossing between Gulangyu Island and Xiamen, the construction of public greening, and the construction of community public activity spaces such as schools all developed rapidly and represented a higher level at that time.

Third, recruitment of residential style. Returning immigrants have come into contact with western civilization and are familiar with various western customs when they make a living overseas. At the same time, they have full feelings for the native land of southern Fujian, which was born and raised in Sri Lanka. The interweaving of the two makes them an intermediary for the blending of Chinese and Western cultures, which is reflected in the architectural style. They build villas, private gardens, and various foreign buildings for themselves and their families, or buy foreign buildings from foreigners for localization. From the 1920s to 1930s alone, 1014 buildings were built on Gulangyu Island by returning overseas immigrants. From
1924 to $1936,75 \%$ of the 970 building licenses issued by Gulangyu Municipal Bureau of Industry belonged to returning overseas immigrants and their families, which greatly changed the settlement pattern and spatial pattern of Gulangyu Island.

Fourth, cultural recruitment. With the support of overseas Chinese returning home, the cultural service facilities on the island have been improved, the cultural living standards of the people have been improved, and Zhongshan Library, the first library in the Xiagu area, has been set up. A large number of religious and non-religious newspapers and periodicals have been published one after another, and the printing industry has also made certain progress, promoting cultural exchanges between China and the West. Local education has also been further improved, such as Xiamen Girls' School established in Lin Qiaozhi and Ciqin Girls' Middle School in Huang Yizhu. More and more Chinese are participating in the network of actors, forming a pattern in which returning immigrants, local elites, and expatriates from many countries participate in the construction and management. In combination with the above, the actor-network translation process as shown in Fig. 8 is formed. In 1941, Japan acquired the management right of Gulangyu Island through military occupation, which finally declared the complete end of Gulangyu Island as a special era of the international community.

Table 2 Composition of actors in the stage of multicultural integration

\begin{tabular}{lll}
\hline Related composition & Category & Content \\
\hline Human actor & Administrative unit & The Qing Government, Municipal Council, Japanese Government \\
Community group & Overseas Chinese, Chinese residents, Foreign nationals \\
& Material element & Capital, Land resources, Municipal facilities, Residential style, Industrial structure \\
& Conceptual elements & Political environment, Laws and regulations, Chinese and Western Cultures \\
\hline
\end{tabular}

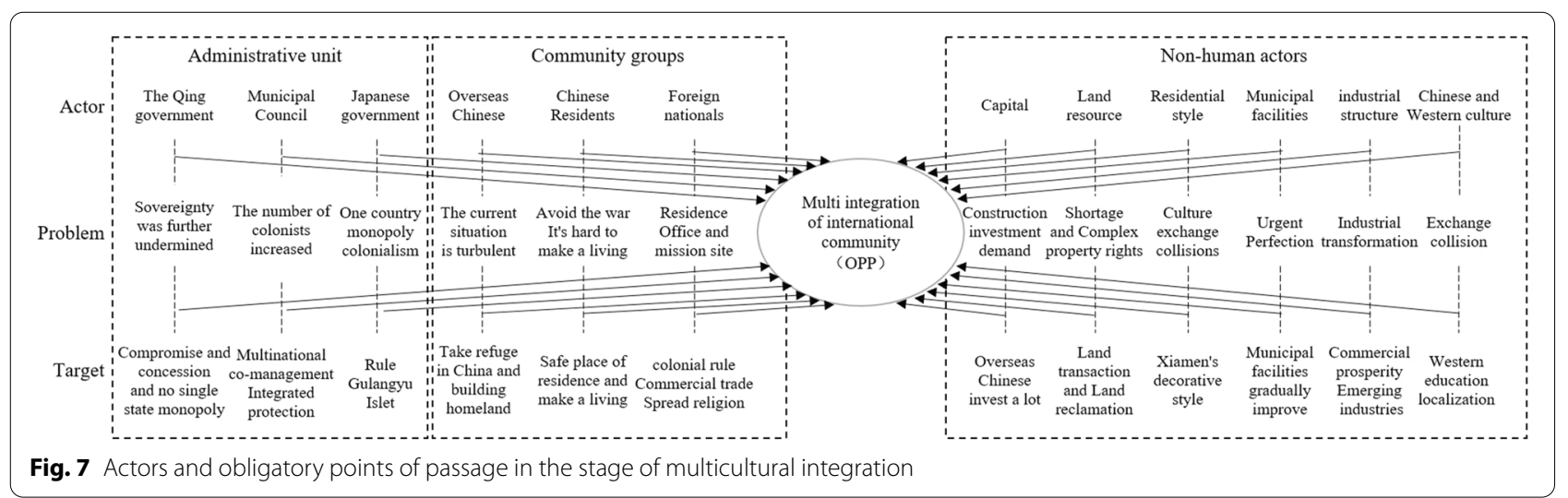




\section{Community spatial evolution under the reconstruction of actor-network}

New actors have further promoted the change of Gulangyu community space through network operation. After entering the twentieth century, the number of Chinese in Gulangyu Island increased rapidly. In 1920, there were about 15,000 Chinese residents on the island, far exceeding foreign nationals. These overseas immigrants with abundant capital are building large-scale projects in Gulang, and the community space of Gulangyu Island has been expanded. Compared with 1900, the eastern and northern docks reclaimed land and increased land resources, and the island area increased from $1.62 \mathrm{~km}^{2}$ in 1900 to $1.71 \mathrm{~km}^{2}$ in 1935 . Due to the limited space of Gulangyu Island and the sequence of building time, overseas Chinese businessmen returning home cannot form a special living space. Their seamless building mode further accelerates the integration of living spaces of different groups, making it difficult for Gulangyu Island to maintain strict zoning (Fig. 9).

With the advancement of community construction, the desolate landform of Gulangyu Island has been gradually changed, more livable areas have been created, and the construction area on Gulangyu Island has been greatly expanded. From 1900 to 1927, the construction area increased at an annual rate of $9.71 \%$. At the same time, the housing construction method is mostly DIY-made, equipped with Xiamen decoration style combining Chinese and Western styles, and the first floor is the same but not repeated. The Bagua Building and Huangjia Garden, which are still preserved today, all represent the exquisite level of construction at that time. The road network system has been comprehensively planned and constructed on the original basis, forming more than 30 roads. Dendritic branches go deep into the community, basically forming the traffic network structure of Gulangyu Island today.

In addition to residential buildings, overseas Chinese have built their own churches, such as Sany Hall (San Yi Tang, 三一堂), as well as public facilities serving the community, such as waterworks, telephone companies, vegetable markets, Yanping Theaters, and clubs. A large number of factories, commercial shops, and warehouses have appeared. Gulangyu's modern residential area, which is dominated by residential functions, is gradually equipped with various commercial functions and public

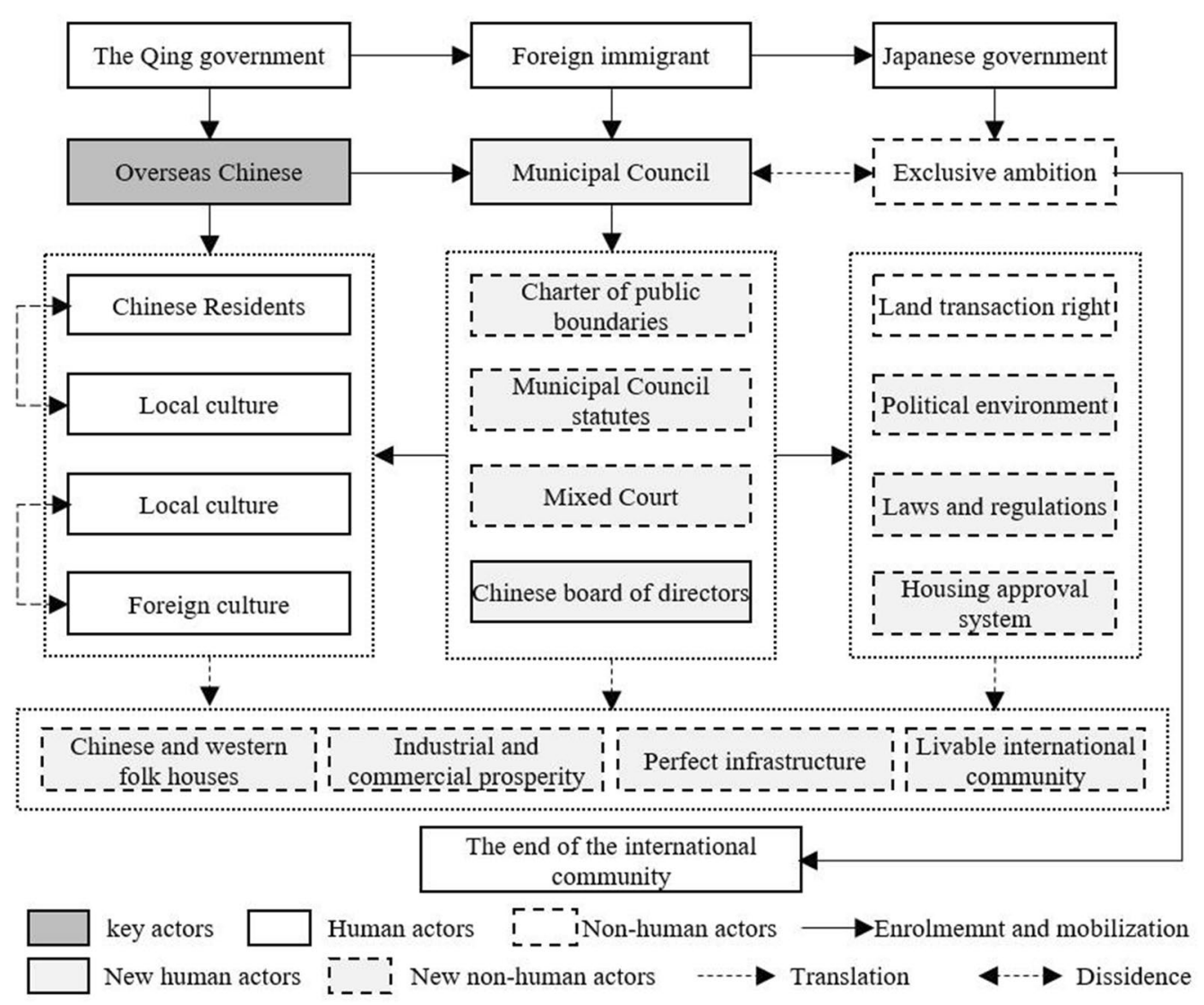

Fig. 8 Actor-network in the stage of multicultural integration 
service functions. The residential form has also gradually changed from traditional village settlements to modern community forms, with international communities showing multiple integrations.

\section{Discussion and conclusion}

\section{Discussion}

The research shows that the spatial evolution of the international community is the result of the joint action of multiple actors led by key actors. The emergence of the historical international community is a process from quantitative change to qualitative change and an advanced stage of multicultural agglomeration. Based on the above-mentioned actor-network, this study analyzes the role of key actors in the process of spatial evolution and summarizes the logic of spatial evolution of the historical international community (Fig. 10).

On the one hand, from the perspective of dynamic mechanism, aborigines, foreign nationals and overseas Chinese gather together in Gulangyu's geographical

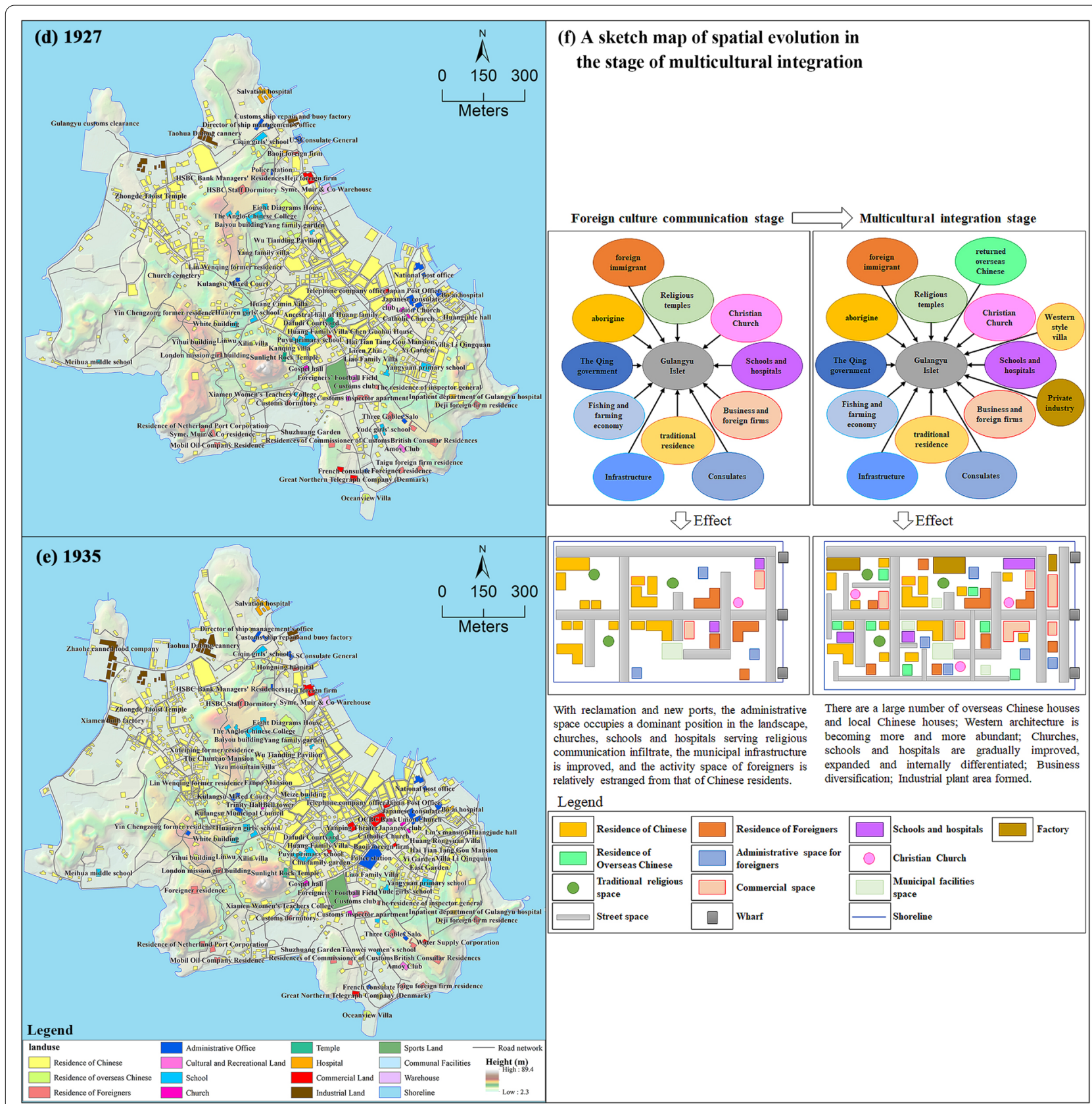

Fig. 9 The spatial evolution of Gulangyu under the reconstruction of actor-network 
space under the joint action of internal driving forces such as material interests and personal reputation, and external pulling forces such as complementary synergy and industrial agglomeration. On the other hand, from the perspective of utility mechanism, the embryonic form of the historical international community, geographical proximity, various formal and informal social network relationships, and division of labor and cooperation based on the industrial chain make them form an organic symbiotic system on Gulangyu Island. With the improvement of infrastructure on the island, the dual effects of spatial diffusion and cultural synergy have been formed; In space, foreign nationals and aborigines are obviously scattered, but they gradually move towards implicit integration in the process of communication; Culturally, with the spread of religion and the establishment of various management systems, the channel of cultural exchange between East and West has been opened. With the space of more and more overseas nationals joining in the follow-up, they brought a lot of money into Gulangyu Island, The Gulangyu region has undergone essential changes. They filled the space between aborigines and foreign nationals, took the initiative to obtain the management right of Gulangyu Island, built buildings with Chinese and Western styles (Xiamen decorative style), further promoted the transformation and renewal of the space, and attracted more overseas Chinese to Gulangyu Island, forming a circular cumulative strengthening effect and realizing the diversified integration of international communities.

As relevant research shows $[3,16,33]$, the interlacing of various interests and the collision of multiple cultures are one of the leading factors to promote the evolution of the spatial form of the international community in Gulangyu Island in modern times, and the development and change of community construction and management, which constitute the distinctive features of community construction and management in Gulangyu Island in modern times. Space practice is the result of the joint action of human and non-human actors, which is rooted in local situations. As Latour, an important interpreter of the actor-network, said: "Facts can only be understood and constructed through practice, and practice is the field of interaction between human and non-human actors" [23]. Therefore, great attention should be paid to local situations in space research, especially the actor of overseas immigrants. Influenced by multicultural factors, Chinese and overseas Chinese reflect their personal ideas to Gulangyu Community, which makes the management mode of Gulangyu Community more characterized by multi-party game, integration, checks and balances, and compromise, which is reflected in its practice of transforming material space. The construction and display significance of Gulangyu spatial practice goes beyond the community life and cultural connotation it carries, and has important reference significance for multicultural integration under the current globalization background.

\section{Conclusion}

Based on the perspective of actor-networks, taking Gulangyu Island from 1840 to 1940 as an example, this study analyzes the composition of actor-network in the two stages of the international community from embryonic form to pluralistic integration and its action path on the spatial evolution of Gulangyu Island. The change of key actors leads to the change of actor-network structure, which promotes the spatial reconstruction and evolution of the Gulangyu international community. The main conclusions are as follows:

First, the earliest development and construction of Gulangyu Island was promoted by neighboring Minnan immigrants, forming three traditional residential settlements: Neicuo'ao, Yanzijiao, and Luer Reef. The land use function is mainly residential land and its affiliated farmland. Ancestral halls and temples are the main public activity spaces for people to use. This traditional settlement form in southern Fujian is far from modern urban communities.

Second, the formation of Gulangyu's modern international community pattern was first promoted by foreign nationals after foreign nationals entered Gulangyu. After that, the construction and management of the Gulangyu community in modern times experienced two periods dominated by different actors, from foreign nationals to overseas immigrants. The social forces composed of different social groups had a great influence on the construction and management of the Gulangyu community in modern times.

Third, the stage of foreign culture dissemination (1840-1902), Gulangyu Island changed from the original traditional community to the embryonic form of an international community. The key actors of community construction in Gulangyu Island are foreign expatriates, and the community development shows the trend of specific zoning, and the community construction mainly serves foreign expatriates. However, limited to the island area and residents affected by different cultures entering Gulangyu Island to live, only relative zoning is maintained. In order to improve their living environment, foreign nationals have carried out basic public facilities construction on Gulangyu Island. Through the establishment of special institutions such as the "Road Cemetery Fund Committee", they have begun to systematically build public infrastructures such as roads, street lamps, and cemeteries. At the same time, they have established modern education, medical care, and health systems 


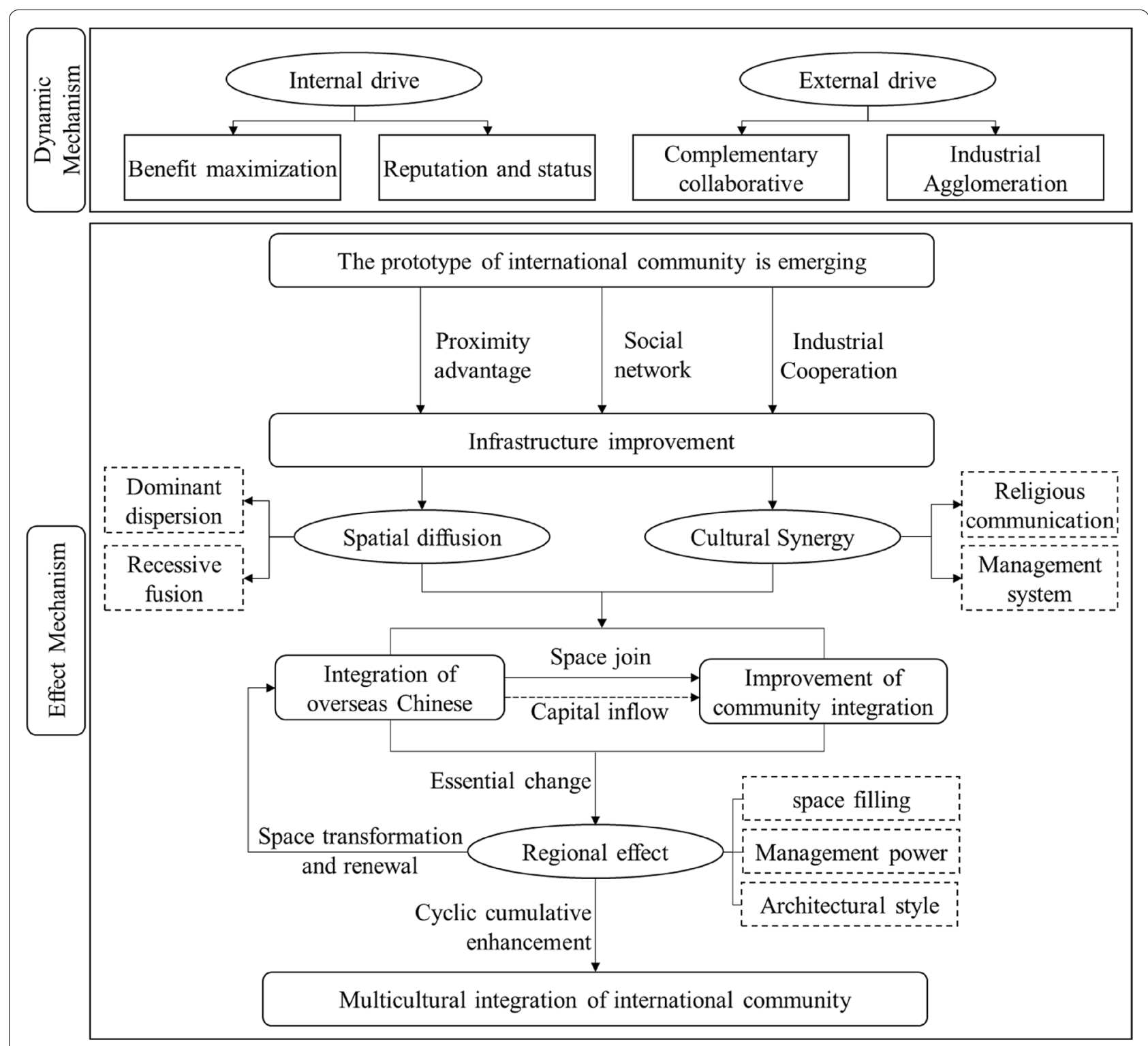

Fig. 10 Spatial evolution logic of historical international community

to promote the germination and initial development of international communities.

Fourth, multicultural integration stage (1903-1940), Gulangyu international community gradually evolved and formed. With the establishment of the Bureau of Public Lands and Industry, influenced by the political environment, the key actors in Gulangyu community construction have changed from foreign expatriates to overseas immigrants from southern Fujian, a large number of overseas Chinese came to Gulangyu Island to settle down. Economic investment and land development have rapidly increased the scale of residential land, breaking the relative gap between Chinese residential areas and foreigners' residential areas. The supporting facilities have been significantly improved. The community space form has shown diversified characteristics and the international community has become more mature. This special international community came to an end after the Japanese military occupation of Gulangyu Island in 1941.

Fifth, the spatial practical experience of Gulangyu historical international community is still of great significance in the current development of multicultural integration under the background of globalization. 


\section{Research inadequacies and prospects}

The shortcomings of this study are as follows: First, limited by historical data, the study can only present the elements on the historical map, and the selected historical time sections are also different in density, which leads to the interpretation of this study only from the key stages; Secondly, when extracting spatial elements based on historical maps, there are certain uncertain factors, which lead to certain errors in data results, and the errors are minimized through multiple checks; Third, due to the lack of more historical data, such as population and economy, this study can only explore heritage sites from the perspective of spatial evolution.

Taking Gulangyu International Community as an example, this study analyzes its spatial evolution mechanism. However, under different natural and social conditions, the network structure of actors is different. Combining GIS spatial analysis methods, strengthening the research of different regional types of space and exploring the common law of spatial evolution of other cultural heritage sites are the future research directions that should be deepened.

\section{Acknowledgements \\ The research is supported by Natural Science Foundation of China (41671141, 42171219 and U1605254), Natural Science Foundation of Fujian Province (2020J01011), Xiamen Science and Technology Bureau Funds(3502Z20183005), Xiamen Construction Bureau Funds(XJK2019-1-9). Therefore, the author would like to thank the National Natural Science Foun- dation of China, Fujian Natural Science Foundation of China, Xiamen science and Technology Bureau and Xiamen Construction Bureau for their technical and financial support.}

\section{Authors' contributions}

All authors read and approved the final manuscript.

\section{Funding}

The research is supported by Natural Science Foundation of China (41671141 and U1605254), Natural Science Foundation of Fujian Province (2020J01011), Xiamen Science and Technology Bureau Funds(3502Z20183005), Xiamen Construction Bureau Funds(XJK2019-1-9).

\section{Availability of data and materials}

All data generated or analyzed during this study are included in this published article.

\section{Declarations}

\section{Competing interests}

The authors declare that they have no competing interests.

\footnotetext{
Author details

${ }^{1}$ Xiamen Key Laboratory of Digital Protection and Application for Cultural Heritage, School of Architecture and Civil Engineering, Xiamen University, Xiamen 361005, Fujian, China. ${ }^{2}$ Urban and Regional Planning, School of Architecture and Civil Engineering, Xiamen University, Xiamen 361005, Fujian, China. ${ }^{3}$ Cultural Heritage and Urban Development, School of Architecture and Civil Engineering, Xiamen University, Xiamen 361005, Fujian, China. ${ }^{4}$ Fujian Key Lab of Sensing and Computing for Smart Cities, School of Informatics, Xiamen University, Xiamen 361005, Fujian, China. ${ }^{5}$ Key Laboratory of Digital Earth Science, Aerospace Information Research Institute, Chinese Academy of Sciences, Beijing 100094, China. ${ }^{6}$ International Centre on Space Technologies for Natural
}

and Cultural Heritage Under the Auspices of UNESCO, Beijing 100094, China. ${ }^{7}$ Department of Geography and Environmental Management, University of Waterloo, Waterloo, ON N2L 3G1, Canada.

Received: 7 August 2021 Accepted: 31 October 2021

Published online: 11 November 2021

\section{References}

1. Feilden BM, Jokilehto J. Management guidelines for world cultural heritage sites. Rome: ICCROM (in collaboration with UNESCO and ICOMOS); 1998.

2. Pan ZG, Yuan QS, Chen SN, Zhang MM. Research and development of digital display and interactive technology of cultural heritage. J Zhejiang Univ. 2020:47(03):261-73.

3. Wang WS. From a historical community to a world heritage: the protection and development of Gulangyu Island in Xiamen. Beijing: China Architecture \& Building Press; 2019. p. 2-11.

4. Jin XB, Pan Q, Yang XH, Bai Q, Zhou YK. Reconstruction of land use patterns in Jiangsu Province in the Mid-Qing Dynasty. J Geog Sci. 2016;26(12):1689-706.

5. Hao LS, Wang XG, Qiao WY, Zhang L. The characteristics of urban spatial expansion in Nanjing since 1936. Geogr Res. 2019:38(04):911-25.

6. Gregory IN, Bennett C, Gilham VL, Southall HR. The Great Britain historical GIS project: from maps to changing human geography. Cartogr J. 2002;39(1):37-49.

7. Schuppert C, Dix A. Reconstructing former features of the cultural landscape near early celtic princely seats in Southern Germany. A GISbased application of large-scale historical maps and archival sources as a contribution to archaeological research. Soc Sci Comput Rev. 2009;27(3):420-36.

8. Kim I-H, Pow CP, Wang Y-C, Feng C-C. Competing space and place identity with landscape change analysis using Web GIS through Singapore historical maps (1828-2015). Singap J Trop Geogr. 2019:40(2):181-98.

9. Zohar M. Follow the road: historical GIS for evaluating the development of routes in the Negev region during the twentieth century. Cartogr Geogr Inf Sci. 2019;46(6):532-46.

10. Liu X, Wang XY. A review of the applied research of actor network theory in the field of human geography. Prog Geogr. 2013;32(07):1139-47.

11. Massey D. Space-time, "science" and the relationship between physical geography and human geography. Trans Inst Br Geogr. 1999;24(3):261-76.

12. Shi S, Ning YM. The evolution of the connotation of "Space" in human geography. Scientia Geographica Sinica. 2005;25(3):340-5.

13. Wang $X, X u L$, Dong $W$, Zhou X. Contextualising a heritage assessment toolkit at the pre-planning stage of the historic urban landscape approach: the case of Mrauk-U. Myanmar Landsc Res. 2021;46(2):273-94.

14. Jiang YC, Jin XB, Xun LJ, Xue QF, Cheng YN, Long Y, et al. Analysis on the expansion process and characteristics of urban built-up areas in the past 600 years: taking the Suhu Area as an example. Urban Plan. 2019;43(12):55-68.

15. Lin T, Li XH, Zhang GQ, Zhao QJ, Cui SH. Analysis on the characteristics and influencing factors of urban spatial expansion of Xiamen Island. Scientia Geographica Sinica. 2010;65(06):715-26.

16. Chen Y. Urban transformation in semi-colonial China: Gulangyu International Settlement, 1903-1937. Singapore: National University of Singapore; 2006.

17. Lv N, Wei Q, Qian Y, Sun Y. Research on Gulangyu Island value system. Chin Cult Herit. 2017;04:4-15.

18. Qiu LL, Zhou Y, Ni ZW, Li Y, Rao JT. Research on the narrative space of historic city based on space syntax. South Archit. 2019;04:110-5.

19. Li Y, Ding YJ, Wang D. A new approach for designing tourist routes by considering travel time constraints and spatial behavior characteristics of tourists. Tour Tribune. 2016;31(09):50-60.

20. Callon M. The sociology of an actor-network: the case of the electric vehicle. London: Palgrave Macmillan; 1986.

21. Latour B. Reassembling the social: an introduction to actor-networktheory. Oxford: Oxford University Press; 2005. 
22. John L. After ANT: complexity, naming and topology. Soc Rev. 1999:47(S1):1-14.

23. Shen P, Li JQ. Research hotspots and frontier trends of actor network theory. J Dialect Nat. 2021;43(11):117-26.

24. Murdoch J. Actor-networks and the evolution of economic forms: combining description and explanation in theories of regulation, flexible specialization, and networks. Environ Plan A. 1995;27(5):731-57.

25. Koo Y, Park SO. Structural and spatial characteristics of personal actor networks: the case of industries for the elderly in Korea. Papers Region Sci. 2012;91(1):43-64.

26. Becerril $\mathrm{H}$. Evictions and housing policy evolution in Rio de Janeiro: an ANT perspective. J Urban Aff. 2017;39(7):939-52.

27. Figueiro AC, de Araujo Oliveira SR, Hartz Z, Couturier Y, Bernier J, Machado Freire MS, et al. A tool for exploring the dynamics of innovative interventions for public health: the critical event card. Int J Public Health. 2017;62(2):177-86.

28. Yan X, He S. The co-evolution of therapeutic landscape and health tourism in bama longevity villages, China: an actor-network perspective. Health Place. 2020;66:102448.

29. Wang Y, Zhu YQ. The spatial evolution path of ancient towns in Jiangnan water village from the perspective of actor networks: taking Zhouzhuang ancient town as an example. Hum Geogr. 2020;35(06):76-84.
30. Murdoch J. Towards a geography of heterogeneous associations. Prog Hum Geogr. 1997;21(3):321-37.

31. Ai SW, Miao CH. "Space of places", "space of flows" and "space of actornetworks": from the perspective of ANT. Hum Geogr. 2010;25(02):43-9.

32. Li QY, Zhan ZX. History of Gulangyu Island. Xiamen: Xiamen University Press; 2013. p. 15-6.

33. Wei Q. Gulangyu historical international community: a community-centric world heritage nomination road. World Archit. 2019;353(11):38-43.

34. Luo QL, Liu QZ, Wang KL, Qiu YD. Discussion on the value recognition, identification method and reuse ideas of disappeared historical relics: taking Wuhan as an example. Urban Plan Forum. 2018;2:106-12.

35. The Editorial Committee of the Series of Books on Gulangyu's Application for World Cultural Heritage. Gulangyu Cultural and Historical Materials (2nd ed.) 2010

36. Xiamen Urban Design and Planning Research Institute. Protection Planning for Historic Buildings on Gulangyu Island in Xiamen (Revision). 2016.

\section{Publisher's Note}

Springer Nature remains neutral with regard to jurisdictional claims in published maps and institutional affiliations.

\section{Submit your manuscript to a SpringerOpen ${ }^{\circ}$ journal and benefit from:}

- Convenient online submission

- Rigorous peer review

- Open access: articles freely available online

- High visibility within the field

- Retaining the copyright to your article

Submit your next manuscript at $\boldsymbol{\nabla}$ springeropen.com 